\title{
Periodicities in the Dynamics of Eruptions of Klyuchevskoi Volcano, Kamchatka
}

\author{
A. Yu. Ozerov, P. P. Firstov, and V. A. Gavrilov \\ Institute for Volcanology and Seismology, Russian Academy of Sciences, \\ Petropavlovsk-Kamchatsky, Russia
}

Detailed studies of volcanic tremor envelopes with frequencies ranging from $5.5 \cdot 10^{-6}$ to $2.5 \cdot 10^{-2} \mathrm{~Hz}(50 \mathrm{hrs}-40 \mathrm{sec}$ ), recorded during the Klyuchevskoi volcano eruptions of 1983 and 1984, revealed five major frequencies: $1.1 \cdot 10^{-2} \mathrm{~Hz}\left(\mathrm{~T}_{1}=1\right.$ $\min 34 \mathrm{sec}), 2.5 \cdot 10^{-3} \mathrm{~Hz}\left(\mathrm{~T}_{2}=6 \mathrm{~min} 10 \mathrm{sec}\right), 4.2 \cdot 10^{-4} \mathrm{~Hz}\left(\mathrm{~T}_{3}=40 \mathrm{~min}\right), 5.1 \cdot 10^{-5}$ $\mathrm{Hz}\left(\mathrm{T}_{4}=5 \mathrm{hrs} 30 \mathrm{~min}\right), 7.7 \cdot 10^{-6} \mathrm{~Hz}\left(\mathrm{~T}_{5}=36 \mathrm{hrs}\right)$, as well as superpositions of their harmonics. In the 1993 eruption, fluctuations in the volcanic tremor envelopes have frequencies of $T_{I}=2 \mathrm{hrs} 48 \mathrm{~min}$ and $\mathrm{T}_{\text {II }}=6 \mathrm{hrs} 12 \mathrm{~min}$, which correspond to periodicities in the dynamics of eruptions identified by visual observations since 1932. The distribution of peak amplitudes has been found to vary in relation to eruption intensity - increasing eruption strength correlates with an increase in the amplitude of low frequency peaks, and vice versa. It is concluded that volcanic tremor allows monitoring of eruption dynamics. Possible reasons for the occurrence of periodicities are discussed, but a comprehensive model for this phenomenon has not yet been developed.

\section{INTRODUCTION}

A basic task of volcanology is the study of the dynamic characteristics of eruptions. Such a study allows identifying major peculiarities of eruptive processes and understanding the basic functioning patterns of active magmatic systems.

Detailed studies were conducted at one of the most active volcanoes in the world-Klyuchevskoi volcano in Kamchatka, Russia, a large basaltic stratovolcano with a height of sea level of $4,822 \mathrm{~m}$. Seismic data indicate that the volcano's feeding system originates in the upper mantle and reaches the surface in the form of a vertical conduit. No large inhomogeneities, which might be interpreted as magmatic chambers within the feeding system, have been discovered. Klyuchevskoi eruptions are characterized by isolated explosions, continuous outburst of incandescent magmatic

Volcanism and Subduction: The Kamchatka Region Geophysical Monograph Series 172

Copyright 2007 by the American Geophysical Union. 10.1029/172GM20 material, and relatively liquid lava flows (Figure 1). Data on the structure of the feeding system of the Klyuchevskoi volcano, on characteristics of its eruptive activity reported by previous investigators, and our long-term studies are reviewed by Ozerov et. al., [1997].

Compositions of all varieties of the volcano's eruption products fall within the common evolutionary calc-alkaline trend of basalts [Ozerov, 2000]. High-aluminous (4.5-6\% $\mathrm{MgO})$ and aluminous $(6-8 \% \mathrm{MgO})$ basalts predominate within the eruptive edifice; magnesium $(8-10 \% \mathrm{MgO})$ and high-magnesium (10-12\% MgO) basalts are subordinate and occur as isolated lava flows and pyroclastic deposits of flank eruptions.

Two terms, "intensity" and "periodicity", of eruption are used in the present paper. These words have not been strictly defined in the volcanological literature. Without any claims to universality, the authors use these terms as follows: intensity of eruption is a descriptive characteristic that is in practice based upon one or more eruption parameters, such as height of bomb or ash ejection, frequency of explosions, size 


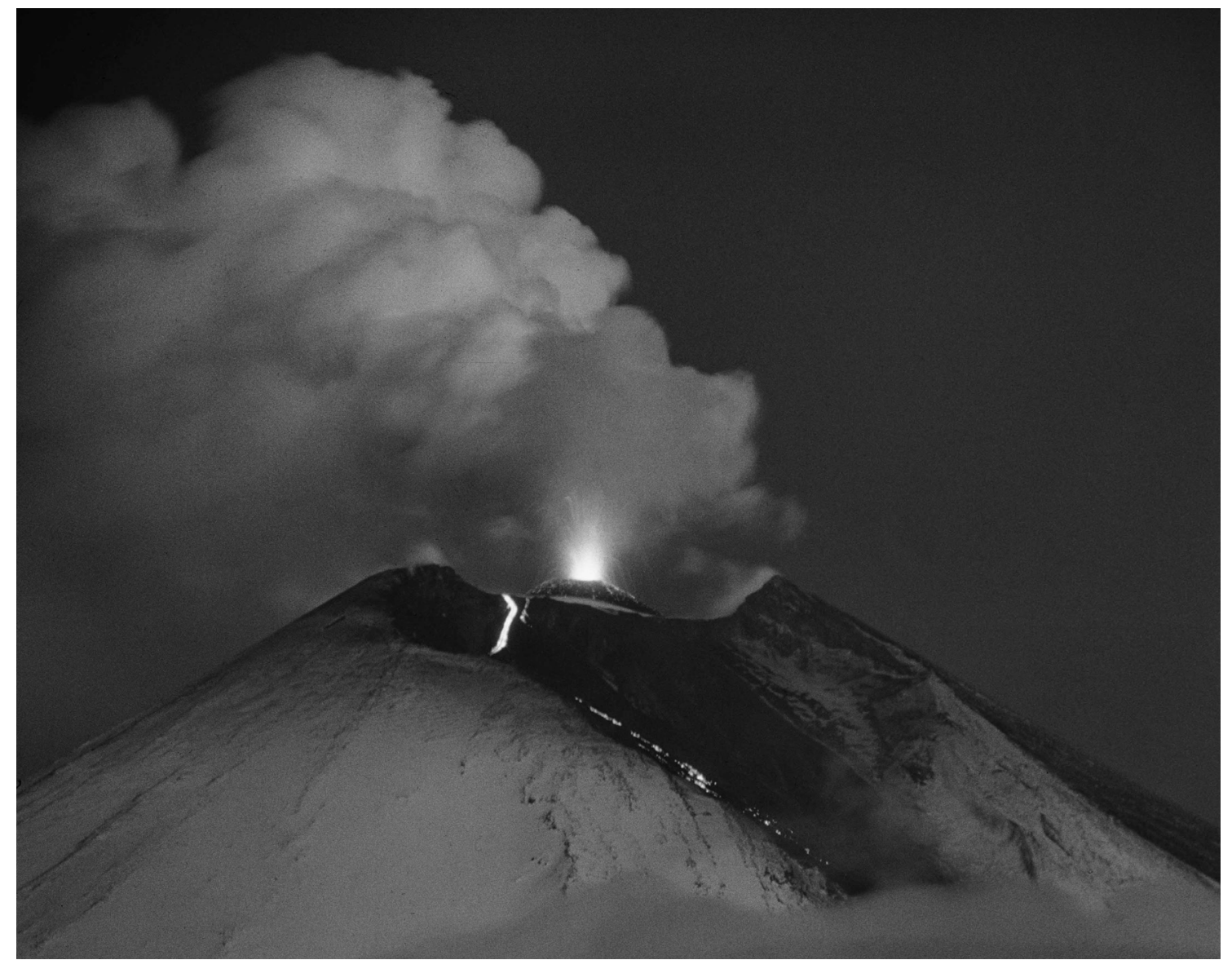

Figure 1. Fire fountains at the Klyuchevskoi volcano summit crater, 1984. Crater diameter $750 \mathrm{~m}$. Bomb ejection height $200 \mathrm{~m}$. Photo by A. Yu. Ozerov.

of ejecta, dimension of eruptive cloud, length of ash plumes, etc. Such characteristics as seismicity (volcanic tremor, volcanic earthquakes) and emission of acoustic energy can also be indicators of the eruption intensity. Thus, the term "intensity of eruption" is used as a parameter, whose pure physical meaning has not yet been determined. Moreover, its meaning can be identified only after developing a physical model for the eruption. In turn, creation of such a model is impossible without searching and systematizing eruption parameters that might allow the physical understanding of the eruptive process. Discovering and describing patterns in eruption parameters is the point of the present paper.

The term "periodicity" in modern volcanological papers can be applied to at least three types of phenomena of completely different nature, intensity and time scale:

1. Periodical recurrence of eruptions at the same volcano (regular successive recurrence of intra-eruptive and eruptive phases). In this case, the period consists of the eruption phase and the dwell phase, their regular recurrence giving the periodicity itself. A period can last from a few months to hundreds or thousands of years. To single out this periodicity, geological and tephrochronological data concerning eruptive events are generally used, as well as statistical treatment of historical information of the volcano behavior.

Examples of such periodicities occurred during the 1986 26-27 day fire fountain episodes at Kilauea volcano, Hawaii [Tilling et al., 1987] and during the 2003-2005 half-year episodes of andesite eruptions at Bezymianny volcano in Kamchatka (as observed by the authors). A possible reason for regular recurrence of events at volcanoes with viscous magmas was discussed by Melnik and Sparks, 1999; Melnik, 2000; Barmin et al., 2002.

2. Periodicity manifesting itself in the course of a single eruptive period of the volcano. For basalt volcanoes, it can be a succession of single explosions (the period consists of an explosion phase and a dwell phase between the explosions), as well as by bomb ejection (the period consists of an intensive fusillade and relative quiet) and by ash emissions (the period combines intervals of tephra production and relative quiet). For andesite volcanoes, periodicity may be present 
in the dynamics of an extrusive dome (period consists of a growth phase accompanied by explosions and/or pyroclastic flows, and a phase of relative quiet). Stable periodicity can be observed with the period lasting for minutes, hours, a few days, or more. Such periodicity can best be revealed as the result of continuous observations, and is rather well determined using seismic methods. This type of periodicity does not always occur in the course of an eruption.

At Klyuchevskoi volcano, periodicity of 6-7 hours was first identified in 1932 during the operation of the Tuila flank breakout [Novograblenov, 1933], as well as a period of 5 minutes in the summit eruption dynamics [Troitsky, 1937]. Periodicity was also reported at Kilauea, Hawaii, the 1959, 1969-72 and 1983-86 eruptions, where rhythmically repeating fountaining cycles were observed lasting from several tens of minutes to a few hours [Swanson et al., 1979; Koyanagi et al., 1987; Wolfe et al., 1987]. During the 1975 Great Tolbachik Fissure Eruption (Kamchatka), a period of 2-3 hours was observed [Gorelchik et al., 1978]. The 1989, 1999 and 2000 eruptions at Etna, Italy, showed periods lasting from an hour to a few hours [Delfa et al., 2001; Privitera et al., 2003]. In the course of the 1991 eruption of Avachinsky volcano (Kamchatka), a 6-hour periodicity was observed (authors' data). The above observations refer to basaltic volcanism; however periodicities lasting for hours or longer occur at andesite volcanoes also. During 1990 eruption of Redoubt volcano (Alaska), two activity intervals were determined, in which dome failure episodes occurred in 4.5 and 7.8 days [Page et al., 1994]. At Soufriere Hills volcano, Montserrat in 1997, periodicities from 8 to 18 hours were determined [Voight et al., 1998; Druitt et al., 2002].

3. Periodicity of single explosions the same eruption episode, consisting of hundreds to thousands of similar explosions. Dwell intervals between the explosions are commonly characterized by a total absence of activity in the crater and, as a rule, last much longer (3-30 minutes) than the explosions themselves.

Explosions proper, presenting the supply of magmatic matter onto the surface, can have several patterns in their development. Some of them fade monotonously and quickly, in $10-15$ seconds. In the course of other, more durable venting events (20-40 seconds, rarely up to one minute and more), modulations might sometimes appear in the acoustic noise intensity and visible volume of the emitting gas with typical period of about 1 second. These fluctuations determine the third type of periodicities in the eruptive activity. Series (pulse groups) are typically observed consisting of 10-20 one second periods. The following pattern occurs: explosion (3-5 seconds), some weakening (10-20 seconds) followed by pulsing (10-25 seconds). Such periodicity can be qualitatively fixed in the course of the regime observation; better, it can be recorded by seismograms, but best and most reliable, is the acoustic record. Periodicities of this kind are typical for andesite volcanism.

This type of periodicities was first mentioned by Tokarev and Firstov [1967] and Farberov et al. [1983] in considering eruptions of Karymsky volcano. Benoit and McNutt [1997] identified this periodicity within the Arsenal Volcano seismic signal and named the process "chugging". The process was studied in detail in the course of joint Russian-American work at the Karymsky volcano during 1996-1999, and by American researchers at the San-Guy volcano eruption [Lees et al., 1997; Johnson and Lees, 1999]. A possible mechanism for this short-period process has been described in the paper by Ozerov et al. [2003].

In the present paper, the second (minute to hour) type of periodicity is considered for single explosions and bomb ejection in the dynamics of the Klyuchevskoi basalt volcano eruption.

\section{OBSERVATIONS AND ANALYSIS}

Investigation of the Klyuchevskoi volcano eruptive process was conducted on three parameters: analysis of historical data on eruption periodicities, detailed visual observations of eruption dynamics, and analysis of seismological data obtained during the eruptions. These volcanological-geophysical surveys made it possible to distinguish periodicities at various levels.

Since 1932, volcanologists have reported periodicities of minutes, hours and multi-hours in the eruptions of the Klyuchevskoi volcano through visual observations of bombfall, lava outburst and steam-gas emissions. Systematization and analysis of these data identified five major groups of periodicities (Figure 2): 1-22 $\mathrm{min}, 28-55 \mathrm{~min}, 1.5-7 \mathrm{hrs}$, $12 \mathrm{hrs}$ and $24 \mathrm{hrs}$ [Ozerov and Konov, 1988; Konov and Ozerov, 1988]. However, visual observations over the course of the eruptions are quite subjective and desultory in character and not always suitable for statistical treatment.

Development of geophysical methods for the studies of volcanic processes allowed continuous surveys of different geophysical fields in the course of the eruption. One of the most striking manifestations of eruption is volcanic tremor [Tokarev, 1982; Koyanagi at al., 1987; Chouet at al., 1994; Julian, 1994; Neuberg, 2000, Chouet at al., 2003]. Monitoring of volcanic tremor is a remote method allowing the study of eruption dynamics, and, in some cases, even the estimation of volume of erupted material [Tokarev, 1981; Gordeev at al., 1985].

We carried out studies of volcanic tremor $(0.8-1.0 \mathrm{~Hz})$ continuously recorded during the eruptions of 1983, 1984 


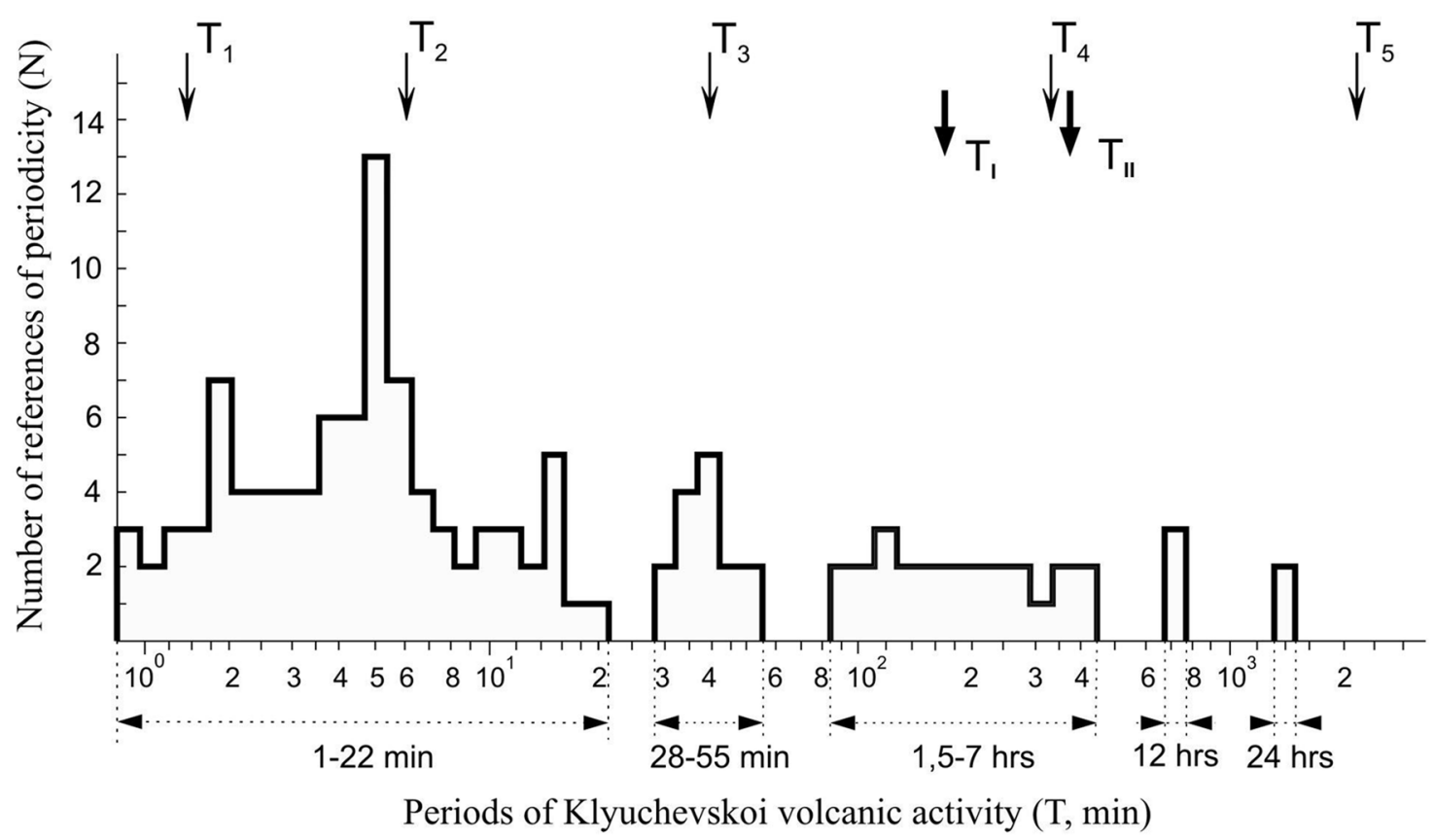

Figure 2. Histogram of observed periodicities in the eruptive activity of the Klyuchevskoi volcano from 1932 to 1978 - by visual data, and by seismic data (1983-84 and 1993). Abscissa axis in the logarithmic scale - periods of volcanic activity in minutes $(\mathrm{T}, \mathrm{min})$; ordinate axis - number of occurrences of individual temporal periodicity $(\mathrm{N})$. Vertical arrows indicate basic periodicities determined by seismic data: thin arrows - for the eruptions of $1983-84\left(\mathrm{~T}_{1}-\mathrm{T}_{5}\right)$, bold ones - for those of $1993\left(\mathrm{~T}_{\mathrm{I}}\right.$ and $\left.\mathrm{T}_{\mathrm{II}}\right)$.

and 1993. The data, obtained at the regional seismic sites (using electrodynamic seismometer SM-2 with $\mathrm{T}_{0}=1.2 \mathrm{sec}$ ) located around the Klyuchevskoi volcano. These were the "Apokhonchich" and "Podkova" stations, placed 14.8 and $14.6 \mathrm{~km}$ away from the crater, respectively. For the 1983 and 1984 eruptions, on the vertical channel, the maximum amplitude of volcanic tremor (displacement_amplitude, measured in microns - $\mu \mathrm{m}$ ) was measured as a basic value. A series of the enveloping maximum tremor amplitudes with sampling ranging from 10 seconds to 15 minutes were developed, with the length of the series ranging from 240 to 6624 points. The subsequent statistical processing was based upon these data. Methods including the calculation of the autocorrelation functions (autocorrelograms) and functions of intercorrelation of two random processes (crosscorrelograms) were used for determining the periodicities. Spectral estimations were made using the method of maximum entropy.

These techniques identified periodicities within the frequency range from $5.6 \cdot 10^{-6} \mathrm{~Hz}\left(\mathrm{~T}_{\max }-50\right.$ hours) to $2.5 \cdot 10^{-2}$ $\mathrm{Hz}\left(\mathrm{T}_{\min }-40 \mathrm{sec}\right)$ [Ozerov and Konov, 1988; Konov and Ozerov, 1988]. In order to test the hypothesis of the influence of lunar and solar tides on eruption dynamics, coefficients have been calculated for correlation between the series of seismological data for three time intervals (June 19 - July 01, 1984; July 09-16, 1984; and August 01-12, 1984) and corresponding series of corrections for tidal gravity variation $(\Delta \mathrm{g}$ values measured in milligals were sampled from the diagram once an hour).

During the 1993 eruption, the Podkova seismic station recorded the rate of ground oscillations in $\mu \mathrm{m} / \mathrm{sec}$. The level logger registered the mean-square value of the ground velocity for volcanic tremor (vertical component) with the time constant of 3200 seconds. This value was used as the intensity of tremor. For the intervals where periodicity occurred, spectral power density of the volcanic tremor intensity in $(\mu \mathrm{m} / \mathrm{s})^{2} /(1 / \mathrm{min})$ was constructed. This method allows recognition of the periods of $15 \mathrm{~min}$ utes and more.

It should be noted that the present research was not aimed at studying the carrier frequency of the Klyuchevskoi volcano tremor $(0.8-1.0 \mathrm{~Hz})$, considered by Tokarev [1966]; Gordeev at al. [1986]. The present work is based on investigating the volcanic tremor envelope, that is, superimposed on the volcanic tremor amplitude-modulated oscillations with a wide range of periods (from $40 \mathrm{sec}$ to $50 \mathrm{hrs}$ ), due to melt movement within the volcano feeding system and magma fragmentation in the effluent channel. 


\section{RESULTS}

Volcanic tremor in 1983-1984 was studied in the most detail. In many cases, distinct periodicities can be traced on the initial rows of the charts. On Figure 3, pulsations of tremor amplitude with periods of 1 minute 34 seconds (a) and 5 hours 30 minutes (b) are clearly seen. However, such an obvious pattern is rare and a thorough study of periods is possible only through the application of a complex statistical processing. Analysis of these results made it possible to single out a basic series of 47 distinct spectral peaks (frequencies), with a number that remained stable for 19 months. The observed changes of the spectral composition of the enveloping volcanic tremor in time, as well as sharp excitation of these frequencies, identified a set of five major frequencies (corresponding periods are given in brackets): $f_{1}=1.1 \cdot 10^{-2} \mathrm{~Hz}\left(\mathrm{~T}_{1}=1 \mathrm{~min} 34\right.$ $\mathrm{sec}) ; f_{2}=2.5 \cdot 10^{-3} \mathrm{~Hz}\left(\mathrm{~T}_{2}=6 \mathrm{~min} 10 \mathrm{sec}\right) ; f_{3}=4.2 \cdot 10^{-4} \mathrm{~Hz}\left(\mathrm{~T}_{3}\right.$ $=40 \mathrm{~min}) ; f_{4}=5.1 \cdot 10^{-5} \mathrm{~Hz}\left(\mathrm{~T}_{4}=5 \mathrm{hrs} 30 \mathrm{~min}\right) ; f_{5}=7.7 \cdot 10^{-6} \mathrm{~Hz}$ $\left(\mathrm{T}_{5}=36 \mathrm{hrs}\right.$ ) (Figure 4$)$. Though the set of spectral peaks of the enveloping tremor remained constant during the 1983-1984

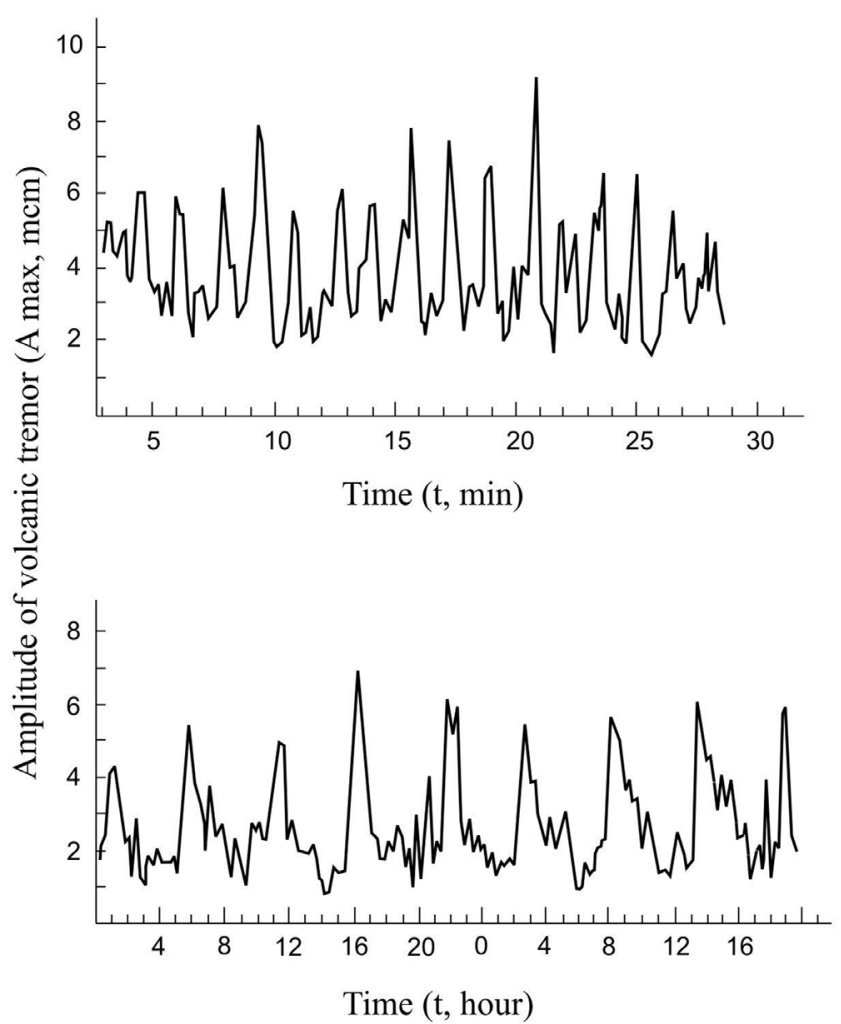

Figure 3. Volcanic tremor amplitude for time intervals: a. - from 03 hours 03 minutes to 03 hours 29 minutes of July 23rd, 1984 (time step is 10 seconds); b. - 00 hours of August 14th, 1984 (time step is 15 minutes). $X$-line - time scale, in fig. (a) - minutes ( $t$, min) and in fig. (b) - hours (t, hour). Y-line - maximum amplitude of volcanic tremor in microns (A max). eruption, their amplitudes varied depending upon the variation of the eruption intensity. When the intensity of the eruption increased, a sharp increase of the amplitude of low frequency peaks took place.

Cross-correlation analysis of corrections series for tidal gravity variations and respective series of values of volcanic tremor envelope has revealed $\sim 12 \mathrm{hrs}$ and $\sim 24 \mathrm{hrs}$ periodicities in the 1984 tremor component (Figure 5). More precise (up to minutes) definition of the periods mentioned is difficult given the method we use. However, comparison of period duration, forms and variation dynamics in crosscorrelograms we obtained with those reported by Melchior [1966] is consistent with the assumption that they are determined by lunar-solar tidal process.

Studies of volcanic tremor during the 1993 eruption showed the following fluctuation (Figure 6): On June 28, about 17:00 UT, when volcanic tremor (I) reaches an intensity of $0.7 \mu \mathrm{m} / \mathrm{s}$, a clear periodic constituent appears, which remained until July 2, 3.5 days later; the amplitude excursion of tremor intensity was $0.2-0.3 \mu \mathrm{m} / \mathrm{s}$. In the power density spectrum of volcanic tremor intensity $-S(\omega)$ - calculated for the given time interval, the spectral maximum has a period of $2 \mathrm{hrs} 48 \mathrm{~min}$. Later, a smooth increase of tremor intensity is observed. On July 10 , at a value of $3 \mu \mathrm{m} / \mathrm{s}$, abrupt deep fluctuations of tremor intensity amplitude occurred, which returned to the periodic oscillations of tremor intensity. This mode remained for 9.5 days, until 12:00 UT on July 20 ; the average level of tremor intensity was $3-4 \mu \mathrm{m} / \mathrm{s}$, with an amplitude excursion of $3.5-6 \mu \mathrm{m} / \mathrm{s}$. For this interval, a spectral power density maximum of tremor intensity occurs at $6 \mathrm{hrs} 12 \mathrm{~min}$. On July 21, about 21:00 UT, the intensity of volcanic tremor starts gradually increasing, and by July 22 it reaches $7.5-8 \mu \mathrm{m} / \mathrm{s}$, while the periodic oscillations of the intensity disappear. Thus, fluctuations with periods of 2 hrs $48 \mathrm{~min}$ and $6 \mathrm{hrs} 12 \mathrm{~min}$ are clearly distinguished in the dynamics of the 1993 eruption (see Figure 6 b and c). The data suggest that with increasing intensity of the eruption, periods that are more durable become active.

Correlation of the results of volcanic tremor studies for 1983-1984 with the periodicities of previous years (19321978) determined by visual observations, shows that four major periods $\left(\mathrm{T}_{1}-\mathrm{T}_{4}\right)$ agree well with four groups of periods singled out in the historical surveys. However, periodicity of $36 \mathrm{~h}\left(\mathrm{~T}_{5}\right)$ has not been reported for any the past eruptions, which might be due to the fact that such a durable periodicity is difficult to document by visual observations. Periods described in the 1993 eruption correspond well to the third group of periodicities singled out from visual data. Results also reveal that $\sim 12$ - and $\sim 24$-h periodicities, conditioned by distorting tidal process, have been found when analyzing historical eruptions of 1932-1978 (Figure 2). 

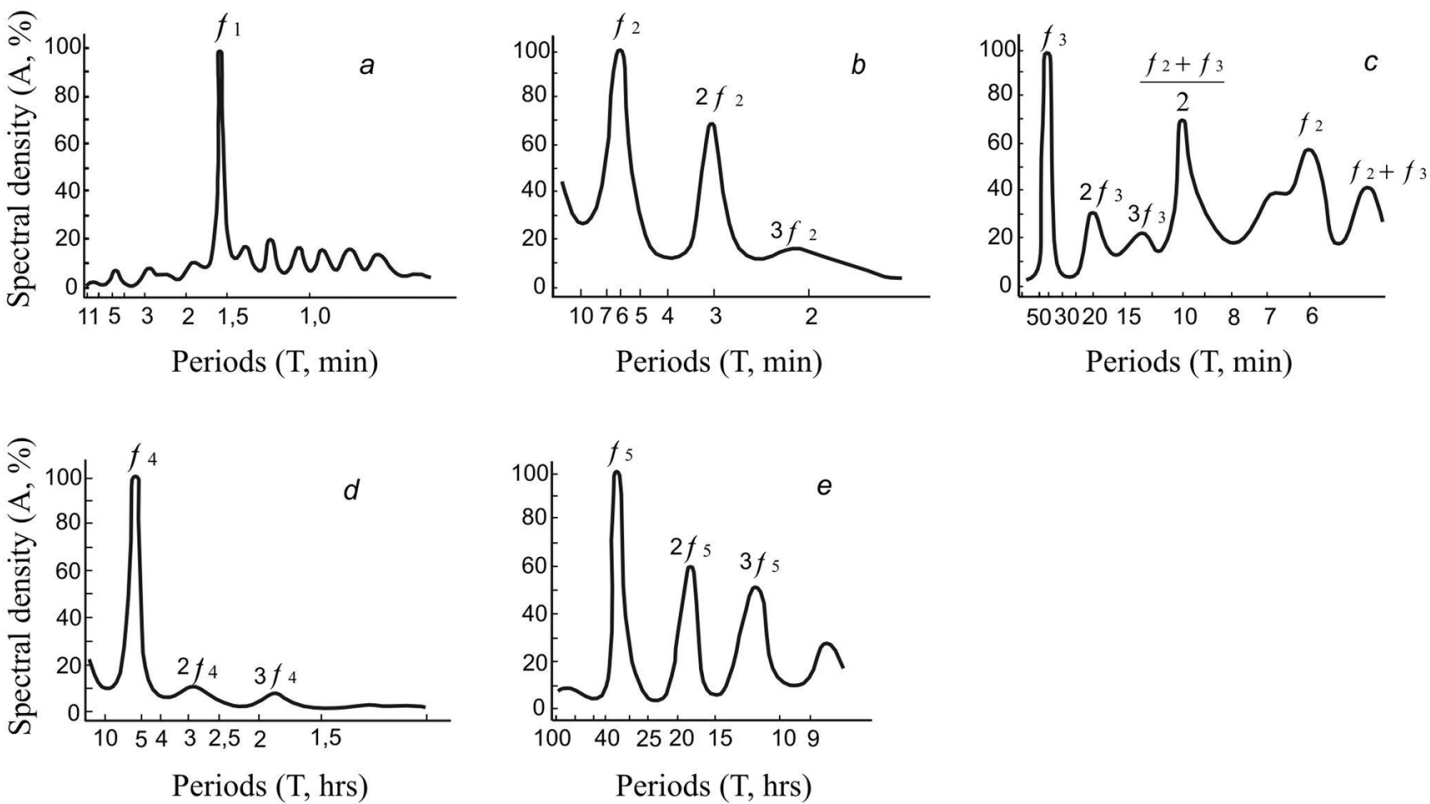

Figure 4. Spectra of the volcanic tremor envelope for various time intervals in 1984: 3-4 a.m., June 23 (a.), 1-2 a.m., August 23 (b.), 3-7 p.m., June 25 (c.), midnight, August 14 - 1 a.m., August 16 (d.), and June 19 - July 2 (e.). X-line - T - periods, in minutes (a., b. and c.) and hours (d. and e.). Y-line - spectral density in \% (A, \%). a.-e.: basic frequencies $\left(f_{1}-f_{5}\right)$ and corresponding periods $\left(\mathrm{T}_{1}-\mathrm{T}_{5}\right) \cdot f_{1}=1.1 \cdot 10^{-2} \mathrm{~Hz}\left(\mathrm{~T}_{1}=1 \min 34 \mathrm{sec}\right) ; f_{2}=2.5 \cdot 10^{-3} \mathrm{~Hz}\left(\mathrm{~T}_{2}=6 \min 10 \mathrm{sec}\right)$; $f_{3}=4.2 \cdot 10^{-4} \mathrm{~Hz}\left(\mathrm{~T}_{3}=40 \mathrm{~min}\right) ; f_{4}=5.1 \cdot 10^{-5} \mathrm{~Hz}\left(\mathrm{~T}_{4}=5 \mathrm{hrs} 30 \mathrm{~min}\right) ; f_{5}=7.7 \cdot 10^{-6} \mathrm{~Hz}\left(\mathrm{~T}_{5}=36 \mathrm{hrs}\right)$. b.-e.: first and second harmonics of basic frequencies (b. $-2 f_{2}$ and $3 f_{2}$, c. $-2 f_{3}$ and $3 f_{3}$, d. $-2 f_{4}$ and $3 f_{4}$, e. $-2 f_{5}$ and $3 f_{5}$ ); c.: superpositions of basic frequencies $f_{2}$ and $f_{3}-\left(f_{2}+f_{3}\right)$ and $\left.\left(f_{2}+f_{3}\right) / 2\right)$.
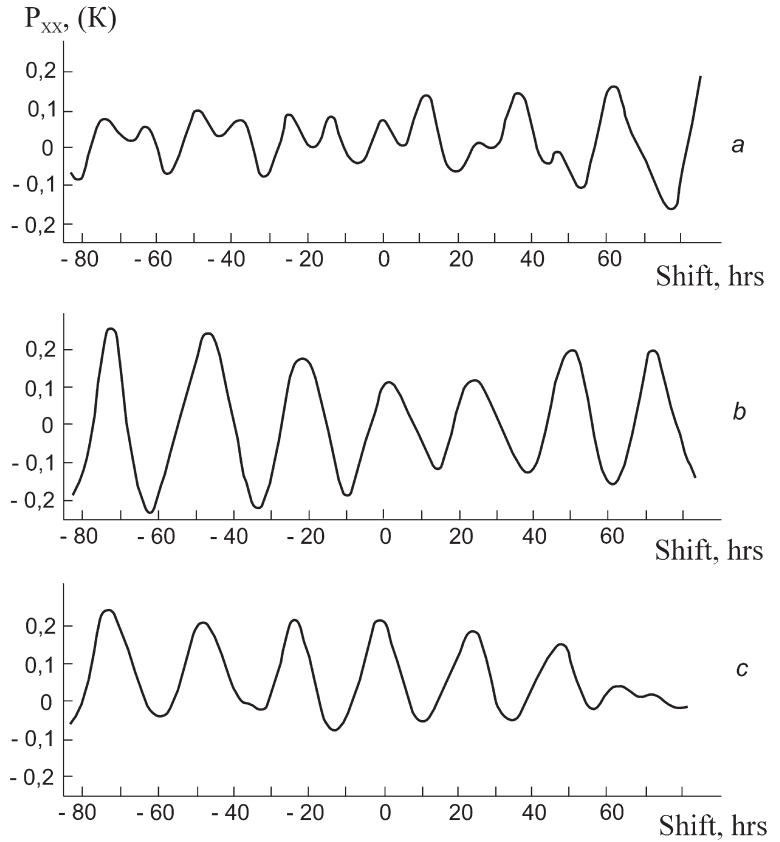

Figure 5. Cross-correlograms of corrections series for tidal gravity variation and corresponding series of tremor envelope values for the intervals of: a. $-1 \mathrm{pm} 19.06 .-1$ am 01.07.1984; b. -2 am 09.07. -1 am 16.07.1984; c. -2 am 01.08. -1 am 12.08.1984

\section{DISCUSSION}

Periodicities in the eruptive activity of the Klyuchevskoi volcano may be accounted for by the existence of natural oscillations of magma (viscoelastic fluid) in the output conduit and magmatic chamber; and/or by resonance oscillations at specific frequencies active under certain conditions. Values of these frequencies are evidently controlled by the geometry of resonators comprising the volcanic system, as well as by physical characteristics of magma and enclosing rocks. In discussing the possible reasons of the occurrence of these periodicities, preference should be given to the processes of degassing in the upper part of the magmatic column. Degassing depends upon pressure variations. The latter may be caused either by magma oscillations in the feeding system of the volcano (system of connected resonators), or by hydrodynamic waves spreading through the magmatic column and formed by resonator fluctuations.

Droznin [1980] and Slezin [1980] report that the diversity of types of volcanic eruptions is well accounted for by the flow regime of a two-phase mixture: melt and gas. Another explanation for periodicities in volcano eruption dynamics may be spontaneous onset of auto-oscillations during the migration of the two-phase mixture along the 
magmatic conduit. Auto-oscillation regimes depending upon the magma discharge rate may occur on different levels of the supply conduit.

Interesting models explaining the abrupt periodical intensifications in the eruption dynamics of Kilauea and Etna volcanoes have been developed. Vergniolle and Jaupart [1986, 1990] assumed that at Kilauea the mechanism of this phenomenon was conditioned by different regimes of two-phase flows, and they created an attractive and original experimental installation. For Etna volcano, Italian researchers developed models involving a near-surface magmatic reservoir. Delfa et al. [2001] considered intensification and weakening of fountaining to be due to reservoir exhaustion and refilling, while Privitera et al. [2003] explained them by redistribution of the gas phase within the reservoir. An indispensable condition in the above models is the presence of a near-surface magmatic chamber, thus involving a structural barrier modifying the parameters of ascending two-phase magmatic mixture.

These models are inapplicable for the Klyuchevskoi volcano, since there is apparently no near-surface chamber in its feeding system [Utnasin et al., 1976; Anosov et al., 1978; Fedotov et al., 1988; Ozerov et al., 1997; Gorelchik et al., 2004]. This is also evidenced by new tomographic imaging
[Lees et al., 2006 (in the present volume)]. It is important that several groups of periodicities (Fig. 2, 3, 4, 6) have been distinguished in the Klyuchevskoi eruption dynamics, which differ in orders of magnitude - from the first minutes to a few tens of hours. Accordingly, following the models suggested by Vergniolle and Jaupart [1990], Delfa et al. [2001] and Privitera et al. [2003], one would have to postulate several chambers greatly differing in size within the feeding systems of the Klyuchevskoi volcano. Therefore, however tempting it might be, to explain the existing number of periodicities by means of structural barriers (magmatic chambers) of various orders of magnitude, it is inconsistent with present knowledge of the Klyuchevskoi volcano structure.

Studies of the stability of Klyuchevskoi magma feeding system under external effects have revealed that eruption dynamics is influenced by lunar-solar tidal deforming processes. Tidal forces may affect a reservoir filled with magma, compressing and stretching it. As a result, magma in the output conduit would oscillate with tidal frequencies corresponding to the periods of 12 and 24 hours. A model for such phenomena has been developed in Shimozuru [1975].

Interpretations suggested thus far do not cover all the possible patterns controlling periodicities at Klyuchevskoi volcano. However, having succeeded in modeling short $(\sim 1 \mathrm{~s})$

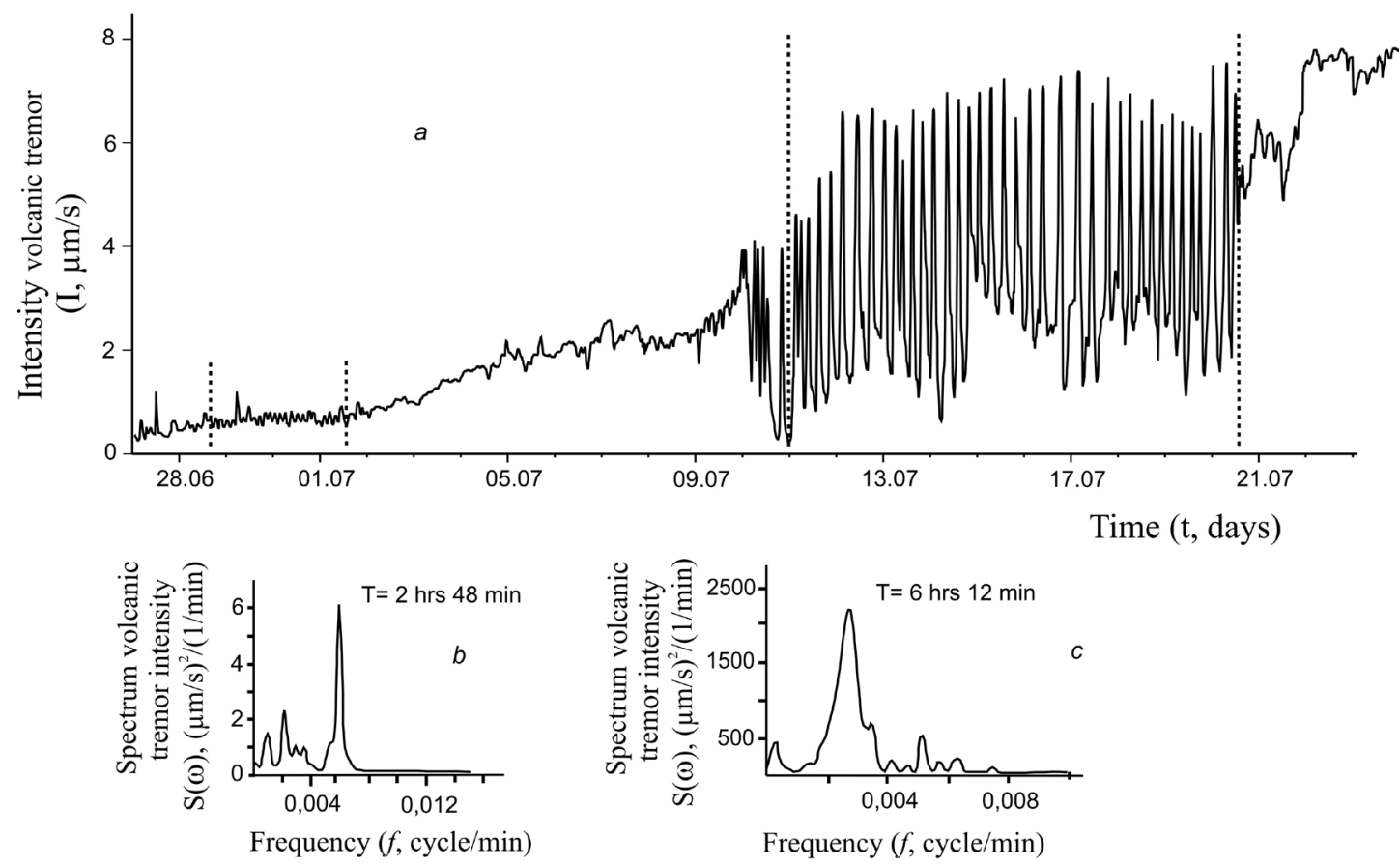

Figure 6. Diagram of changes of the volcanic tremor intensity for the interval from June 27 until July 24, 1993 (a.), and power density spectra of the volcanic tremor intensity (b. and c.) for two time intervals depicted in the (a.) diagram by vertical dotted lines: 7 p.m., June 28 - 3 a.m., July 2 (b.), and midnight, July 11 - 2 p.m., July 20 (c.). In fig. (a): X-line - time, measured in days (t, days), Y-line - Intensity of volcanic tremor $(\mathrm{I}, \mu \mathrm{m} / \mathrm{s})$. In fig. (b) and (c): X-line - frequency measured in the cycles per minute $\left(f\right.$, cycle/min); Y-line - spectral density power of volcanic tremor intensity - $\mathrm{S}(\omega),(\mu \mathrm{m} / \mathrm{s})^{2} /(1 / \mathrm{min})$. 
periodicities in the eruptive process of Karymsky volcano [Ozerov et al., 2003], we continue our studies of the periodicities' at Klyuchevskoi in order to find the causes of this phenomenon. Results obtained will contribute to understanding the dynamics of magmatic systems. Knowledge of patterns of changes in eruption intensity as recorded in seismic data may contribute to better evaluation of risks to aviation and local settlements during an eruption.

Acknowledgments. Authors acknowledge Evgenii I. Gordeev, Jaroslav D. Muraviov, Alexander S. Konov, Andrei I. Farberov, Gennadii I. Anosov, Valentina I. Gorelchik, Aleksandr S. Storcheus, John C. Eichelberger, Maxim G. Gavrilenko, Iskander R. Abubakirov, Olga S. Chubarova, Olga I. Diachkova, Annie F. Sashenkova for their contribution to the research. The authors would like to thank Dr. Tom Miller for his great assistance in editing and preparing the manuscript for publication. The present research is supported by the grants of RFBR № 06-05-64590-a, 07-05-10052k, 05-05-64730-a and Grants of FEB RAS 06-III-A-08-331, 06-IIIВ-08-368, 07-III-Д-08-095.

\section{REFERENCES}

Anosov, G. I., S. K. Bikkenina, and A. A. Popov (1978), Deep seismic sounding of Kamchatka, Nauka, Moscow, 129 p.

Barmin, A. A., O. Melnik, and R. S. J. Sparks (2002), Periodic behavior in lava dome eruptions, Earth and Planetary Science Letters, 199, 173-184.

Benoit, J. P., and S. R. McNutt (1997), New constraints on source of volcanic tremor at Arsenal Volcano, Costa Rica, using broadband seismic data, Geophys. Res. Lett., 24, 449-452.

Chouet B., P. Dawson, T. Ohminato, M. Martini, G. Saccorotti, F. Giudicepietro, G. De Luca, G. Milana, and R. Scarpa (2003), Source mechanisms of explosions at Stromboli Volcano, Italy, determined from moment-tensor inversions of very-longperiod data, J. Geophys. Res., 108 (B1), 2019, doi:10.1029/2002 JB001919.

Chouet, B. A., R. A. Page, C. D. Stephens, J. C. Lahr, and J. A. Power (1994), Precursory swarms of long-period events at Redoubt Volcano (1989-1990), Alaska: Their origin and use as a forecasting tool, J. Volcanol. Geotherm. Res., 62, 95-135.

Delfa, S. La., G. Patane, R. Clocchiatti, J. L. Joron, and J. C. Tanguy (2001), Activity of Mount Etna preceding the February 1999 fissure eruption: inferred mechanism from seismological and geochemical data, J. Volcanol. Geotherm. Res., 105, 121-139.

Druitt, T. H., S. R. Young, B. Bartie, C. Bonadonna, E. S. Calder, A. B. Clarke, P. D. Cole, C. L. Harford, R. A. Herd, R. Luckett, G. Ryan, and B. Voight (2002), Episodes of cyclic Vulcanian explosive activity with fountain collapse at Soufriere Hills Volcano, Montserrat, Druitt, T.H., Kokelaar, B.P. (eds), The Eruption of Soufriere Hills Volcano, Montserrat, from 1995 to 1999. Geological Society, London, Memoirs, 21, 281-306.

Droznin, V. A. (1980), Physical model for the volcanic process, Nauka, Moscow, 91 p.
Farberov, A. I., A. B. Storcheus, and E. S. Pribulov (1983), Studies of weak seismicity of Karymsky volcano, August 1978, Volcanology and Seismology, 3, 78-89.

Fedotov, S.A., N.A. Zharinov, and V.I. Gorelchik (1988), Deformation and earthquakes of Klyuchevskoy volcano, Volcanology and Seismology, 2, 3-42.

Gordeev, E. I. (1985), The Main Properties of Volcanic Tremor of Some Kamchatkan Volcanoes, Volcanology and Seismology, 3, 68-77.

Gordeev, E. I., Yu. Yu. Mel'nikov, V. I. Sinitsin, and V. N. Chebrov (1986), Volcanic tremor of the Klyuchevskoy volcano (eruption of the apical crater in 1984), Volcanology and Seismology, 5, $39-53$.

Gorelchik V. I., V. T. Garbuzova, and A.V. Storcheus (2004), Deepseated processes beneath Klyuchevskoi volcano as inferred from seismological date, Volcanology and Seismology, 6, 21-34.

Gorelchik V. I., V. V. Stepanov, and V. P. Khanzutin (1978), Volcanic tremor at the Great Tolbachik Fissure Eruption in 1975 // In the book "Geological and geophysical data on the Great Tolbachik Fissure Eruption in 1975-1976", Moscow, Nauka, 146-159.

Johnson, J. B., and J. M. Lees (1999), Plugs and Chugs - Strombolian activity at Karymsky, Russia, and Sangay, Ecuador, J. Volc. Geotherm. Res., 101, 67-82.

Julian, D. R. (1994), Volcanic tremor: Nonlinear excitation by fluid flow, J. Geophys. Res, 99, No B6, 11,859-11,877, June 10.

Konov, A. S. and A. Yu. Ozerov (1990), Klyuchevskoi eruptive activities and volcanic tremors: correlation of periodic events, Volcanology and Seismology, Vol. 10, No. 3, 360-385. (Translated from Russian-Volcanology and Seismology, 3, 21-38, 1988).

Koyanagi, R. Y., B. Chouet, and K. Aki (1987), Origin of volcanic tremor in Hawaii. 1. Data from the Hawaiian volcano observatory 1969-1985, U.S. Geol. Surv. Prof. Pap., 1350, 1221-1257.

Lees J. M., N. Symons, O.S. Chubarova, V. I. Gorelchik, and A.Yu. Ozerov (2006), Tomographic Images of Klyuchevskoy Volcano Pwave Velocity, Submitted to AGU Monograph: Volcanism and Tectonics of the Kamchatka Peninsula and Adjacent Arcs, "in press".

Lees, J. M., A. Y. Ozerov, and E. I. Gordeev (1997), Quasi-periodic Eruptions on Karymsky Volcano, Kamchatka, 1996, AGU Spring Meeting. V22A-05.

Melchior, P. (1966), The Earth Tides, Pergamon Press, OxfordLondon-Edinburg-New-York-Paris-Frankfurt, 445 p.

Melnik, O. (2000), Dynamics of two-phase conduit flow of highviscosity gas-saturated magma: large variations of sustained explosive eruption intensity, Bull. Volcanol., 62, 153-170.

Melnik, O. and R. S. J. Sparks (1999), Nonlinear dynamics of lava dome extrusion, Nature, 492, 4 November, 37-41.

Neuberg, J. (2000), External modulation of volcanic activity, Geophys. J. Int., 142, 232-240.

Novograblenov, P. T. (1933), Lateral crater eruption at Klyuchevskoy volcano, Proceedings State Geographic Society, 52-54.

Ozerov, A. Y. (2000), The evolution of high-alumina basalts of the Klyuchevskoy volcano, Kamchatka, Russia, based on microprobe analyses of mineral inclusions, J. Volcanol. Geotherm. Res., 95, 65-79. 
Ozerov, A. Yu. and A. S. Konov (1988), Regularities the dynamics of the Klyuchevskoy volcano eruption, Proceeding Kagoshima International Conference of Volcanoes, Japan, 63-65.

Ozerov, A. Yu., A. A. Ariskin, Ph. Kyle, G. E. Bogoyavlenskaya, and S. F. Karpenko (1997), Petrological-geochemical model for genetic relationships between basaltic and andesitic magmatism of Klyuchevskoi and Bezimyannyi volcanoes, Kamchatka, Petrology, Vol. 5, № 6, 550-569. (Translated from RussianPetrologiya, Vol. 5, No. 6, 614-635, 1997).

Ozerov, A. Yu., I. O. Ispolatov, and J. M. Lees (2003), Modeling Strombolian eruptions of Karymsky volcano, Kamchatka, Russia, J. Volcanol. Geotherm. Res., 122, 265-280.

Page, R. A., J.C. Lahr, B.A.Chouet, J. A.Power, and C. D. Stephens (1994), Statistical forecasting of repetitious dome failures during the waning eruption of Redoubt Volcano, Alaska, February-April 1990, J. Volcanol. Geotherm. Res., 62, 183-196.

Privitera, E., T. Sgroi, and S. Gresta (2003), Statistical analysis of intermittent volcanic tremor associated with the September 1989 summit explosive eruptions at Mount Etna, Sicily, J. Volcanol. Geotherm. Res., 120, 235-247.

Shimozuru, D. (1975), Lava lake oscillations and the magma reservoir beneath a volcano, Bull. Volcanologigue, XXXIX -4, 1-11.

Slezin, Yu. B. (1980), Interaction of particles in the permanent gas-pyroclastic flow in the volcanic channel, Volcanology and Seismology, 5, 40-47.

Swanson, D. A., D. A. Duffield, D. B. Jackson, and D. W. Peterson (1979), Chronological narrative of the 1969-1971 Mauna Ulu eruption of Kilauea volcano, Hawaii, U.S. Geol. Surv. Prof. Pap., 1056, 1-55.

Tokarev, P. I. (1966), Eruptions and seismic regime of the Klyuchevskoi group volcanoes, Nauka, Moscow, $120 \mathrm{p}$.
Tokarev, P. I. (1981), Volcanic tremor, Volcanology and Seismology, 3, 55-72.

Tokarev, P. I. (1982), Volcanic Micro-Tremors, Volcanology and Seismology, 6, 56-78.

Tokarev, P. I. and P. P. Firstov (1967), Seismological studies of Karymsky volcano, Bulluten' Vulkanol. Stanciy, 43, 9-22.

Troitsky A. P. (1937) On the behavior of the Klyuchevskoy volcano crater in 1935, Proceedings State Geographic Society, vol. XIX, 6, 969-974.

Vergniolle, S. and C. Jaupart (1986), Separated two-phase flow and basaltic eruptions, J. Geophys. Res., 91, 12842-12860.

Vergniolle, S., and C. Jaupart (1990), The dynamics of degassing at Kilauea volcano, Hawaii, J. Geophys. Res., 95, 2793-2809.

Voight, B., R. P. Hoblitt, A. B. Clarke, A. B. Lockhart, A. D. Miller, L. Lynch, J. McMahon (1998), Remarkable cyclic ground deformation monitored in real-time on Montserrat, and its use in eruption forecasting, Geophys. Res. Lett., 25, No 18, 3405-3408, September 15.

Wolfe, E. W., M. O. Garcia, D. B. Jackson, R. Y. Koyanagi, C. A. Neal, and A. T. Okamura (1987), The $\mathrm{Pu}^{\prime} \mathrm{u}^{\prime} \mathrm{O}^{\prime} \mathrm{o}$ eruption of Kilauea volcano, episodes 1-20, January 3, 1983 to June 8, 1984, U.S. Geol. Surv. Prof. Pap., 1350, 471-508.

Utnasin, V. K., A. I. Abdurakhmanov, G. I. Anosov, Yu.A. Budyansky, V.I. Fedorchenko, Ye.K. Markhinin, and S.T. Balesta (1976), Types of magma foci of island arc volcanoes and their study by the method of deep seismic sounding of Kamchatka, Volcanoes and Tectonosphere, Tokai University Press, 123-137.

A. Yu. Ozerov, P. P. Firstov and V. A. Gavrilov, Institute for Volcanology and Seismology, FED RAS, Piip blvd., 9, Petropavlovsk-Kamchatsky, 683006, Russia. (ozerov@ozerov.ru; first41@ mail.ru; vgavr@kscnet.ru) 
